\title{
Correction to: Largely Unchanged Annual Incidence and Overall Survival of Pleural Mesothelioma in the USA
}

\author{
Hari B. Keshava ${ }^{1} \cdot$ Andrew Tang $^{1} \cdot$ Hafiz Umair Siddiqui ${ }^{1} \cdot$ Siva Raja $^{1}$. \\ Daniel P. Raymond ${ }^{1} \cdot$ Alejandro Bribriesco $^{1} \cdot$ James Stevenson $^{1} \cdot$ Sudish C. Murthy $^{1}$ • \\ Usman Ahmad ${ }^{1}$
}

Published online: 10 September 2019

(C) Société Internationale de Chirurgie 2019

\section{Correction to: World J Surg}

$$
\text { https://doi.org/10.1007/s00268-019-05132-6 }
$$

The following disclaimer is missing from the original article:

The data used in the study are derived from a de-identified NCDB file. The American College of Surgeons and the Commission on Cancer have not verified and are not responsible for the analytic or statistical methodology

employed, or the conclusions drawn from these data by the investigator.

Publisher's Note Springer Nature remains neutral with regard to jurisdictional claims in published maps and institutional affiliations.

The original article can be found online at https://doi.org/10.1007/ s00268-019-05132-6.

Usman Ahmad

ahmadu@ccf.org

1 Department of Thoracic and Cardiovascular Surgery, Taussig

Cancer Center, Heart and Vascular Institute, Cleveland

Clinic, 9500 Euclid Avenue / Mail Stop J4-1, Cleveland,

OH 44195, USA 